\title{
EDITORIAL
}

\section{THE MYCOBAC'TERIA}

The peculiar response of the tissues of the host to Mycobacteria or acid-fast bacilli is monocytic. This is the central lesson brought out in a series of illumınatıng articles recently published in the form of a symposium.* (See also p.Iog).

The Acid-Fast Family consists of the various strains of tubercle and leprosy bacilli, the organism of Johne's disease, and a number of acid-fast strains which do not produce disease, such as the timothy grass and smegma bacilli. In all the diseases caused by these germs there is one feature in common, the response of the monocyte to the invasion of the host. This cell may respond in one of two very different ways. It may regard the mycobacterial invader as a friend, grant it hospitality in its interior, supply it with nourishment, allow it to multiply, and convey it through the body. At last, vacuolated and bloated with multiplying rods in its cytoplasm, it comes to a standstill and dies, and its burden of bacilli may give rise to a new focus of disease. On the other hand, the monocyte may take a hostile view of the invader and do its utmost to surround, localise and destroy its enemy. Rapid mytotic division gives rise to multiple cells which, as they ingest and destroy bacilli, produce the characteristic epithelioid cells and, if many bacilli have to be dealt with, may produce a few multinucleated cells of the Langhan's type. The epithelioid cells surrounded by lymphocyte infiltration take the form of compact tubercles; with clear-cut margins, generally ranged round small blood vessels.

The relative degree of tolerance of the cells for the bacilli found in these two types depends on a number of factors: (I) The nature and virulence of the organism and the consequent resistance which it can offer to the host. More or less virulent strains of tubercule bacilli can be dissociated by growth on media of varying $\mathrm{pH}$. Whether a similar dissociation of lepra bacilli could be achieved if once we had a strong in vitro culture, is a question which must for the present remain unanswered. (2) The toxicity of substances released by the destruction of the acid-fast bacillus. Not only do these substances cause tissue destruction, but they also

* Tuberculosis and Leprosy, the Mycobacterial Diseases, published by The American Association for the Advancement of Science, 1938. The Science Press Printing Company, Lancaster, Pennsylvania. 
sensitize the monocytes and increase their power of resisting and destroying the invader. (3) The natural or acquired resistance of the host to the particular mycobacterium by which it is invaded. In some this resistance is so strong that the organism cannot multiply at all, as the bovine bacillus in the fowl, or human leprosy in any genus but that of man; in others the growth is rapid and unrestricted; while between these two there is resistance sufficient to restrict, but not to exterminate, the invader. Later, the tolerant host may become sensitized with the production of acquired immunity, or the resistant host may become desensitized.

The nature of the disease produced is dependent partly on the natural or acquired resistance of the body to the germ, and partly on the selectivity of the latter for certain tissues of the body. Thus in the resistant human subject human tubercle bacilli affect chiefly bone, skin and lymph nodes, in the less resistant the lungs and other internal organs. The germ of human leprosy differs from all other mycobacteria in its affinity for the peripheral nerves. While nerves are invaded by bacilli both in patients with high and in those with low resistance, it is in the former (the neural type) that inflammatory reaction is chiefly produced, followed by blocking and destruction of nerve fibres. Similarly, Johne's bacillus has an almost exclusive affinity for the bowel.

Allergy in tuberculosis differs from anaphalactic sensitization to foreign protein. The former is a result of sensitization of the cell itself to the protein products of the tubercle bacillus, in which the role of anti-bodies cannot be demonstrated; the latter is a result of the interaction of demonstrable antibodies with antigen where sensitization of the cells is not demonstrable.

We may take it that immunity in leprosy is associated with allergic rather than anaphylactic sensitization. There is possible evidence of local cell immunization. The tuberculoid lesion spreading at the margin and healing up in the centre may be explained on the assumption that the infection in its march leaves behind locally immune tissues. But this local immunity is not necessarily dependent on sensitized cells; Topley* states that " it would seem that any treatment which induces a local mobilization or concentration of histiocytes will confer on the treated area an increased resistance, which will last as long as the local cellular changes persist." The activation of lepromatous lesions known as " lepra reaction" does not as a rule affect all the lesions of the body simultaneously or even all parts of any one lesion. This also would suggest local sensitization. On the other hand, when 
reaction of the major tuberculoid takes place it is common for the lesions all over the body to react simultaneously; it would appear that a sudden and universal sensitization has taken place of the cells in the vicinity of the bacilli, and so strong is this sensitization that spontaneous healing not uncommonly occurs.

Phospholipin, a lecithin-like substance derived from different strains of tubercle baclli, when injected into the pleural cavity of the rabbit produces tubercular tissue in the pleura consisting of epithelioid cells closely packed and infiltrated with lymphocytes; that is to say, it produces lesions histologically like the hard tubercles of tuberculosis and the tuberculoid lesions of leprosy.

This usetul series of articles, embodying much of the most recent work done on the subject, brings into perspective the relationship of these diseases, which have so much in common and yet diner so materially from each other. One can understand the origin of human tuberculosis from that of the lower animals; but what of the origin of human leprosy? Was it originally a disease of animals now extinct?

A distinct stride forward was made in the improvement of the classitication of leprosy at the Cairo Conference. Many of us have, however, felt two dithculties about the terms there devised. (I) I ne term " neural " may be taken by the uninitiated to imply that the nerves are not involved except in the neural form, whereas the infection of the nerves may be even more severe in the lepromatous than in the neural type, although that severer intection calls forth less tissue response, and therefore produces slighter sensory and trophic changes. Also, the typical tuberculoid lesion does not end in the skin, it spreads up into the nerve, producing essentially the same histological changes there. Even when the skin is not affected the pure nerve lesion is still of a tuberculoid nature as much as is the lesion affecting only the skin. Why then not term the resistant form of leprosy " tuberculoid"? (2) There are many cases which are hard to classify under either of the two main types; at least this is so in India and Africa, and I have recently been told that the same holds good in Malaya. This is the case in a large proportion of lepromatous cases which begin with sensory and trophic signs, accompanied by swelling and tenderness of nerves; also in well established cases with tuberculoid lesions which not infrequently develop lepromatous lesions; and, at least in some countries, there are many indeterminate cases between the two main definite types (see Dr. Davey's paper p.92). Dr. Pupo's suggested changes in the present 
classification (see p.II7) following on the lines put forward by Jeanselme, meet both these difficulties in a practical manner.

It is questionable, however, whether it would not be better on the part of the South American leprologists to delay action, and adhere to the classification adopted at the Cairo Conference, until such time as further general discussion at a future international conference may lead to general agreement. The advantages of a universally accepted classification more than outweigh any slight inherent defects.

The life of the leper is one that is full of discouragements. It is therefore incumbent on those who are in any way connected with his treatment or hopes of recovery that they should be particularly careful not to raise false hopes in his mind, which may later lead to cruel disappointment. Many errors have been made in claiming the efficacy of anti-leprosy drugs, either as the result of the sanguine temperament of the doctor, or on account of his lack of familiarity with the course of leprosy, which has led him to mistake anergic suppression of lesions for real and permanent improvement. Much more culpable is the conduct of those who, for commercial reasons, make big claims which have not been fully established by carefully planned and controlled experiments.

Reference was made in the last number of Leprosy Revieru, p. 43, to the severer type of leprosy in Europeans as compared with Bantus. In considering the possible reasons for this, the abstract on Negro Skin (p.II5) is of interest. 